\title{
Rapid-Air-Dry Papanicolaou Stain in Canine and Feline Tumor Cytology: A Quantitative Comparison with the Giemsa Stain
}

\author{
Mariko SAWA ${ }^{1)}$, Akira YABUKI ${ }^{1) *}$, Noriaki MIYOSHI ${ }^{2)}$, Kou ARAI $^{3)}$ and Osamu YAMATO ${ }^{1)}$ \\ 1) Laboratory of Veterinary Clinical Pathology, Department of Veterinary Medicine, Kagoshima University, Kagoshima 890-0065, Japan \\ ${ }^{2)}$ Laboratory of Veterinary Pathology, Department of Veterinary Medicine, Kagoshima University, Kagoshima 890-0065, Japan \\ 3) Kagoshima University Veterinary Teaching Hospital, Kagoshima University, Kagoshima 890-0065, Japan
}

(Received 4 February 2012/Accepted 24 April 2012/Published online in J-STAGE 18 May 2012)

\begin{abstract}
The Papanicolaou stain is a gold-standard staining method for tumor diagnosis in human cytology. However, it has not been used routinely in veterinary cytology, because of its complicated multistep procedure and requirement for wet fixation. Currently, a rapid Papanicolaou stain using air-dried smears is utilized in human cytology, but usefulness of this rapid-air-dry Papanicolaou (RAD-Pap) stain in the veterinary field has not been fully evaluated. The purpose of this study was to evaluate the usefulness of the RAD-Pap stain by using quantitative analysis. Air-dried impression smears were collected from tumor specimens and stained with RAD-Pap and Giemsa. Twelve parameters representing the criteria of malignancy were quantitated, and characteristics of the RAD-Pap were evaluated statistically. The RAD-Pap stain could be applied to all the smears, and images of nucleoli and chromatin patterns were clear and detailed. In quantitative analysis with the RAD-Pap stain, but not with the Giemsa stain, dispersion of nucleolus size and dispersion of nucleolus/nucleus ratio in malignant tumors were significantly higher than those in benign tumors. These findings demonstrated that the RAD-Pap stain was useful for obtaining detailed nuclear information, and the ability to differentiate benignity and malignancy by nucleolus findings was a principal advantage of this stain. This RAD-Pap stain could be routinely used as a supportive staining method in veterinary diagnostic cytology. KEY WORDS: canine, cytology, feline, quantitative analysis, rapid-air-dry Papanicolaou.
\end{abstract}

doi: 10.1292/jvms.12-0046; J. Vet. Med. Sci. 74(9): 1133-1138, 2012

The Papanicolaou (Pap) stain is used as a polychrome staining technique in human medicine [11], particularly in vaginal cytology for cervical cancer screening and sputum cytology for lung cancer screening. The advantage of the Pap stain is the ability to yield detailed information regarding nucleoli and chromatin pattern in the tumor cell nuclei. This is extremely important for diagnostic cytology, because nuclear detail is used to determine whether tumor cells are benign or malignant [13]. For this reason, Pap is a gold-standard staining method for diagnosis of neoplastic diseases in human medicine, and it is used for exfoliative cells or fine-needle biopsy specimens [8, 21]. However, the traditional Pap stain requires wet fixation and a multistep staining procedure. Therefore, the Pap stain has not been used routinely for veterinary diagnostic cytology.

A rapid Pap stain using air-dried smears was developed by Yang and Alvarez $[17,20]$. The procedure of this rapidair-dry Papanicolaou (RAD-Pap) stain is relatively simple and yields high quality images similar to those with traditional Pap. Following the development of the RAD-Pap stain, many modified procedures were reported, and the quality of the samples stained with RAD-Pap was noted as equal or superior to that of the traditional Pap [4]. In human medicine, the RAD-Pap stain has been used for cytological

*Correspondence to: Yabuki, Y., Laboratory of Veterinary Clinical Pathology, Department of Veterinary Medicine, Kagoshima University, 1-21-24 Korimoto, Kagoshima 890-0065, Japan.

e-mail: yabu@agri.kagoshima-u.ac.jp

(C)2012 The Japanese Society of Veterinary Science specimens such as fine-needle aspirations [7, 20], scrape smears [1, 3], and body-fluid smears [18], and usefulness of the RAD-Pap has been demonstrated in these reports.

The difference between RAD-Pap and traditional Pap is not only in the staining procedure but also in the sample preparation. Briefly, RAD-Pap uses air-dried smears, while traditional Pap uses wet-fixed smears. This technical characteristic of the RAD-Pap is a major advantage for veterinary cytology, because the air-dried smear is the most common sample preparation technique in veterinary cytology. Therefore, the RAD-Pap stain should be useful for microscopic diagnosis of neoplastic tissues in veterinary medicine. The RAD-Pap stain for tumor cytology in dogs and horses [5], and exfoliative vaginal smear cytology in dogs [12], has been previously reported; however, the usefulness of the RAD-Pap stain for veterinary tumor cytology has not been fully evaluated, and no quantitative evidence has been reported previously. Therefore, in the present study, canine and feline tumor specimens were stained with RAD-Pap and quantitatively compared with Giemsa-stained specimens.

\section{MATERIALS AND METHODS}

Sample collection: Impression smears were prepared from 57 surgical tumor-biopsy specimens that were obtained from dogs and cats admitted to Kagoshima University Veterinary Teaching Hospital, Japan. All biopsy specimens were histopathologically diagnosed by veterinary pathologists and included 34 epithelial tumors, 15 mesenchymal tumors, and 8 round cell tumors (Table 1). Impression smears were immediately air-dried and stained with RAD-Pap or 
Table 1. List of tumors evaluated in the present study

\begin{tabular}{|c|c|c|}
\hline \multicolumn{2}{|r|}{ Histopathological diagnosis } & \multirow{2}{*}{$\begin{array}{c}\text { Number } \\
5\end{array}$} \\
\hline \multirow{16}{*}{$\begin{array}{l}\text { Epithelial } \\
\text { tumor }\end{array}$} & Perianal gland adenoma & \\
\hline & Squamous cell carcinoma & 5 \\
\hline & Adenocarcinoma & 4 \\
\hline & Sebaceous epithelioma & 3 \\
\hline & Transitional cell carcinoma & 3 \\
\hline & Adrenocortical adenoma & 2 \\
\hline & Mammary anaplastic carcinoma & 2 \\
\hline & Tubulopapillary carcinoma & 2 \\
\hline & Adenosquamous cell carcinoma & 1 \\
\hline & Apocrine adenocarcinoma & 1 \\
\hline & Benign complex adenoma & 1 \\
\hline & Hepatocellular carcinoma & 1 \\
\hline & Meibomian adenoma & 1 \\
\hline & Mammary simple adenoma & 1 \\
\hline & Renal carcinoma & 1 \\
\hline & Sebaceous adenoma & 1 \\
\hline \multirow{7}{*}{$\begin{array}{l}\text { Mesenchymal } \\
\text { tumor }\end{array}$} & Melanoma & 4 \\
\hline & Fibrosarcoma & 3 \\
\hline & Hemangiosarcoma & 3 \\
\hline & Osteosarcoma & 2 \\
\hline & Chondrosarcoma & 1 \\
\hline & Liposarcoma & 1 \\
\hline & Malignant peripheral nerve sheath tumor & 1 \\
\hline \multirow{3}{*}{$\begin{array}{l}\text { Round cell } \\
\text { tumor }\end{array}$} & Cutaneous plasmacytoma & 4 \\
\hline & Lymphoma & 3 \\
\hline & Histiocytic sarcoma & 1 \\
\hline Total & & 57 \\
\hline
\end{tabular}

Giemsa (Wright's Giemsa or May-Grünwald Giemsa) within $24 \mathrm{hr}$. The present RAD-Pap stain was performed according to Minato's protocol [9] with slight modification (Table 2).

Quantitative analysis: On average, 3 digital images per sample were taken for both the RAD-Pap- and Giemsastained smears. These images were taken of thin layer smears without any artifacts. Approximately 20 tumor cells per stain of each sample were selected, and the following parameters were measured using digital imaging software (SigmaScan Pro 5.0; Systat Software, Chicago, IL, U.S.A.): (A) the number of nucleoli, (B) the maximum cell diameter, (C) the maximum nuclear diameter, and (D) the maximum diameter of the largest nucleolus in each nucleus. Then, nucleus/cell ratio and nucleolus/nucleus ratio were defined as $\mathrm{C} / \mathrm{B}$ and $\mathrm{D} / \mathrm{C}$, respectively. The degree of dispersion in each parameter was represented by the standard deviation (SD) of the mean value for each parameter of each sample.

Statistical analysis: Statistical analysis was performed using PASW software (IBM SPSS Statistics, Armonk, NY, U.S.A.). Correlations between the RAD-Pap and Giemsa stains in each parameter were tested by Pearson's productmoment correlation coefficient, and values of $P<0.05$ were defined as statistically significant. Differences between RAD-Pap and Giemsa in each parameter were tested by Wilcoxon signed-rank test at a significance level of $P<0.05$. Differences between benign $(n=14)$ and malignant $(n=31)$
Table 2. Procedure of the rapid-air-dry (RAD) Papanicolaou stain

\begin{tabular}{cll}
\hline Step & Reagent & Amount/duration \\
\hline 1 & Physiological saline & $30 \mathrm{sec}$ \\
2 & $95 \%$ ethanol & $30 \mathrm{sec}$ \\
3 & Alcoholic formalin & $10 \mathrm{sec}$ \\
4 & Tap water & 5 slow dips \\
5 & Gill's hematoxylin $\mathrm{V}^{*}$ & 1 min \\
6 & Tap water & 5 slow dips \\
7 & $0.5 \%$ HCl in $70 \%$ ethanol & $3-5$ slow dips \\
8 & Tap water & 5 min \\
9 & $95 \%$ ethanol & $5-10$ slow dips \\
10 & Orange G* & 1 min \\
11 & $95 \%$ ethanol & $5-10$ slow dips \\
12 & $1 \%$ acetic acid in $95 \%$ ethanol & $5-10$ slow dips \\
13 & $1 \%$ phosphotungstic acid in $95 \%$ ethanol & $5-10$ slow dips \\
14 & EA 50* & 1 min \\
15 & $95 \%$ ethanol & $5-10$ slow dips \\
16 & $100 \%$ ethanol & Direct stream \\
17 & Xylene & 1 min (3 changes) \\
18 & Mount coverslip & \\
\hline Total time & Maximum 15 min \\
\hline
\end{tabular}

*: Muto Pure Chemicals, Tokyo, Japan.

tumors were tested using the Mann-Whitney $U$-test at a significance level of $P<0.05$, but round cell tumors and melanomas were excluded from this test, because malignancy of those tumors is difficult to determine like other tumors. Benignity and malignancy in each tumor were determined by histopathological diagnosis.

\section{RESULTS}

Cytomorphological appearance of RAD-Pap-stained specimens: In the present protocol, the RAD-Pap stain was completed within 15 min. This RAD-Pap stain provided clear polychromatic images with an erythrocyte-free background. Nucleoli of various sizes and shapes were stained vivid orange or red, and the examiner could easily detect minute spotted nucleoli (Fig. 1). Nuclear chromatin pattern was exceptionally clear with the RAD-Pap stain, and the examiner could easily detect various chromatin patterns such as smooth, finely stippled, lacy, ropy, coarse, clumped, and smudged. These nuclear findings were able to be observed, even if the specimens were too thick.

Correlations between the RAD-Pap and Giemsa stains: Although significant correlations between the RAD-Pap and Giemsa stains were detected in most parameters, no strong correlations were detected except for that in mean nucleus/ cell ratio (Table 3 ). In addition, no significant correlations were detected in dispersion of nucleus/cell ratio and dispersion of number of nucleoli.

Differences between the RAD-Pap and Giemsa stains: For number of nucleoli, dispersion of number of nucleoli, and dispersion of nucleolus/nucleus ratio, the values of the RAD-Pap stain were significantly higher than those of the Giemsa stain (Table 4). However, in cell, nucleus, and nucleolus sizes, the values of the RAD-Pap stain were signif- 

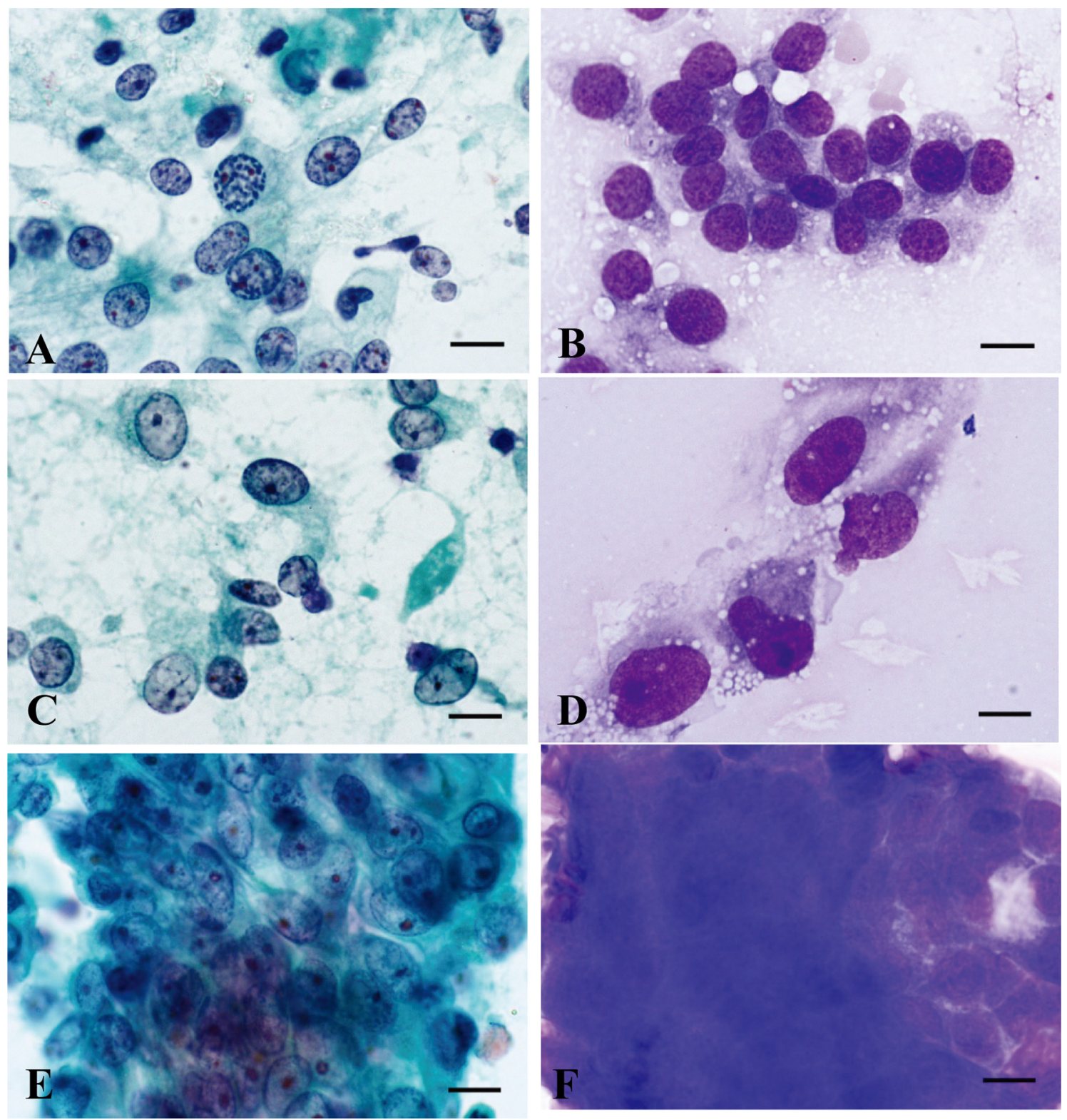

Fig. 1. Light micrographs from rapid-air-dry (RAD) Papanicolaou (Pap)- and Giemsa-stained samples. A and B: Renal carcinoma from a dog. C and D: Hemangiosarcoma from a dog. E and F: Transitional cell carcinoma from a dog. A, C, and E: RAD-Pap stain. B, D, and F: Giemsa stain. With the RAD-Pap stain, sizes of cells, nuclei, and nucleoli are smaller than those with Giemsa. Multiple minute nucleoli and various chromatin patterns such as smooth, finely stippled, ropy, and clumped are clearly observed with the RAD-Pap stain. In thick specimens, nuclear details are observed with the RAD-Pap stain (Panel E), but not with the Giemsa stain (Panel F). Bars=10 $\mu \mathrm{m}$.

icantly lower than those of the Giemsa stain. No significant differences between the RAD-Pap and Giemsa stains were detected in the other parameters.

Differences between benignity and malignancy: In the RAD-Pap stain, significant differences between benignity and malignancy were detected in dispersion of nucleolus size and dispersion of nucleolus/nucleus ratio, and malignant tumors showed higher values than those of benign tumors (Table 5). No significant differences were detected in the other parameters. In the Giemsa stain, significant differences between benignity and malignancy were detected in dispersion of cell size, nucleus diameter, dispersion of nucleus size, and dispersion of nucleus/cell ratio, and malignant tumors showed higher values than those of benign tumors.

\section{DISCUSSION}

In the present study, clear and vivid-colored nucleoli were observed in the RAD-Pap-stained smears, and detectability of nucleoli with the RAD-Pap stain was markedly superior to 
Table 3. Correlations between the RAD-Papanicolaou and Giemsa stains

\begin{tabular}{lc}
\hline Parameter & $\mathrm{R}$ \\
\hline Mean cell size & 0.505 \\
Dispersion of cell size & 0.415 \\
Mean nucleus size & 0.637 \\
Dispersion of nucleus size & 0.54 \\
Mean nucleus/cell ratio & 0.715 \\
Dispersion of nucleus/cell ratio & $\mathrm{NS}$ \\
Number of nucleoli & 0.407 \\
Dispersion of number of nucleoli & $\mathrm{NS}$ \\
Mean nucleolus size & 0.341 \\
Dispersion of nucleolus size & 0.302 \\
Mean nucleolus/nucleus ratio & 0.435 \\
Dispersion of nucleolus/nucleus ratio & 0.374 \\
\hline
\end{tabular}

R: Correlation coefficient, NS: Not significant. that with the Giemsa stain, and it was demonstrated that the RAD-Pap stain was superior in detecting anisonucleoliosis between tumor cells. Briefly, in dispersion of nucleolus size and dispersion of nucleolus/nucleus ratio, malignancy could be detected with RAD-Pap but not with Giemsa. Because the largest nucleolus in each nucleus was measured in the present study, these parameters represented anisonucleoliosis between tumor cells. Anisonucleoliosis within the same nucleus is an important malignant criterion [15]. Although the present study could not evaluate anisonucleoliosis within the same nucleus quantitatively, minute spotted nucleoli were satisfactorily detected with the RAD-Pap stain, and this malignant criterion could be identified more clearly with RAD-Pap than with Giemsa. Regarding the enlargement of nucleoli in malignant tumors, superiority of RAD-Pap was not demonstrated in the present study. In fact, nucleolar size with the RAD-Pap stain was significantly smaller than that with Giemsa. In correlation between the RADPap and Giemsa, no strong correlations were found in the

Table 4. Differences between the RAD-Papanicolaou and Giemsa stains

\begin{tabular}{lcc}
\hline \multirow{2}{*}{ Parameter } & RAD-Pap & Giemsa \\
\cline { 2 - 3 } & Mean \pm SD & Mean \pm SD \\
\hline Mean cell size $(\mu \mathrm{m})$ & $14.57 \pm 4.24^{*}$ & $17.42 \pm 4.45$ \\
Dispersion of cell size & $119.64 \pm 56.78$ & $121.66 \pm 52.94$ \\
Mean nucleus size $(\mu \mathrm{m})$ & $6.25 \pm 1.22^{*}$ & $8.18 \pm 1.45$ \\
Dispersion of nucleus size & $38.48 \pm 18.35$ & $41.97 \pm 18.34$ \\
Mean nucleus/cell ratio & $0.48 \pm 0.13$ & $0.50 \pm 0.13$ \\
Dispersion of nucleus/cell ratio & $0.10 \pm 0.04$ & $0.09 \pm 0.03$ \\
Number of nucleoli & $1.15 \pm 0.54^{*}$ & $0.47 \pm 0.45$ \\
Dispersion of number of nucleoli & $0.76 \pm 0.29^{*}$ & $0.51 \pm 0.32$ \\
Mean nucleolus size $(\mu \mathrm{m})$ & $1.32 \pm 0.44^{*}$ & $1.89 \pm 0.43$ \\
Dispersion of nucleolus size & $12.69 \pm 7.02$ & $15.01 \pm 6.47$ \\
Mean nucleolus/nucleus ratio & $0.21 \pm 0.05$ & $0.22 \pm 0.04$ \\
Dispersion of nucleolus/nucleus ratio & $0.06 \pm 0.03^{*}$ & $0.05 \pm 0.02$ \\
\hline
\end{tabular}

*: Significantly different from the Giemsa stain.

Table 5. Differences between benign and malignant measurements with the RAD-Papanicolaou and Giemsa stains

\begin{tabular}{|c|c|c|c|c|}
\hline \multirow{3}{*}{ Parameter } & \multicolumn{2}{|c|}{ RAD-Pap } & \multicolumn{2}{|c|}{ Giemsa } \\
\hline & Benign & Malignant & Benign & Malignant \\
\hline & Mean \pm SD & Mean \pm SD & Mean \pm SD & Mean \pm SD \\
\hline Mean cell size $(\mu \mathrm{m})$ & $17.24 \pm 3.75$ & $14.85 \pm 3.75$ & $18.75 \pm 1.60$ & $18.33 \pm 4.47$ \\
\hline Dispersion of cell size & $105.24 \pm 37.47$ & $131.74 \pm 61.17$ & $103.99 \pm 15.03$ & $140.76 \pm 53.39^{*}$ \\
\hline Mean nucleus size $(\mu \mathrm{m})$ & $6.10 \pm 1.23$ & $6.45 \pm 1.08$ & $7.38 \pm 0.85$ & $8.68 \pm 1.48^{*}$ \\
\hline Dispersion of nucleus size & $32.27 \pm 13.28$ & $43.90 \pm 20.61$ & $31.99 \pm 11.23$ & $47.83 \pm 21.11 *$ \\
\hline Mean nucleus/cell ratio & $0.39 \pm 0.08$ & $0.48 \pm 0.13$ & $0.42 \pm 0.07$ & $0.49 \pm 0.10$ \\
\hline Dispersion of nucleus/cell ratio & $0.07 \pm 0.02$ & $0.09 \pm 0.04$ & $0.06 \pm 0.03$ & $0.10 \pm 0.03^{*}$ \\
\hline Number of nucleoli & $0.99 \pm 0.49$ & $1.24 \pm 0.61$ & $0.39 \pm 0.33$ & $0.50 \pm 0.50$ \\
\hline Dispersion of number of nucleoli & $0.67 \pm 0.29$ & $0.82 \pm 0.32$ & $0.37 \pm 0.25$ & $0.56 \pm 0.33$ \\
\hline Mean nucleolus size $(\mu \mathrm{m})$ & $1.14 \pm 0.33$ & $1.32 \pm 0.36$ & $1.73 \pm 0.39$ & $2.02 \pm 0.39$ \\
\hline Dispersion of nucleolus size & $8.63 \pm 4.02$ & $13.38 \pm 6.78^{*}$ & $12.00 \pm 4.70$ & $16.85 \pm 6.99$ \\
\hline Mean nucleolus/nucleus ratio & $0.18 \pm 0.04$ & $0.20 \pm 0.04$ & $0.22 \pm 0.04$ & $0.22 \pm 0.04$ \\
\hline Dispersion of nucleolus/nucleus ratio & $0.04 \pm 0.02$ & $0.06 \pm 0.02 *$ & $0.05 \pm 0.02$ & $0.05 \pm 0.02$ \\
\hline
\end{tabular}

Benignity and malignancy were based on histopathological diagnosis, and only epithelial and mesenchymal tumors (excluding melanoma) were evaluated. *: Significantly different from the benign measurement. 
parameters except for that in mean nucleus/cell ratio. This finding indicates that the RAD-Pap stain can extract a range of cytomorphological information that differs from that of Giemsa-stained samples.

Generally, cell and nuclear sizes with the traditional Pap stain are smaller than those with the Giemsa stain [14], and these differences are explained by the sample preparation method. Briefly, the cells appear much smaller with wet fixation than with air-dried preparation, because the cells are three-dimensional in the former and two-dimensional in the latter [16]. Due to this effect of wet fixation, the ability to detect anisocytosis and anisokaryosis, which are criteria of malignancy, with the traditional Pap stain is inferior to that with the Giemsa stain. The RAD-Pap stain compensates for this inferiority of the traditional Pap stain, because the RADPap uses air-dried smears; therefore, tumor cell sizes are larger than those with the traditional Pap $[13,16]$. However, the results of the present microscopic examination did not completely adhere to this theory. Cell bodies and nuclei from the RAD-Pap-stained smears were observed to be smaller than those from the Giemsa-stained smears. This finding was demonstrated quantitatively, and the sizes of cells and nuclei with the RAD-Pap stain showed lower values than those with Giemsa. In dispersion of nuclear size, although no significant difference between the RAD-Pap and Giemsa stains was detected, malignancy according to this parameter was detected with Giemsa only. These decreased cell and nucleus sizes with the RAD-Pap stain might be caused by the rehydration process prior to fixation with alcoholic formalin. The process of rehydration is essential for the RADPap stain [19]. In a previous study, several solutions were tested as rehydration solutions, and it was demonstrated that physiological saline was superior to the other solutions [2]. Following this report, many of the RAD-Pap protocols, including that of the present study, adopt physiological saline as the rehydration solution $[6,18,22]$. However, decrease of cell size probably occurred during the rehydration step with physiological saline, and there may be other suitable rehydration solutions for the RAD-Pap stain that prevent cell shrinkage.

The present RAD-Pap stain required only 15 min from fixation to coverslip mounting, which was quicker than the traditional Giemsa stain. This rapid stain provided highquality images of nuclei and polychromatic cytoplasm in samples from dogs and cats. Chromatin patterns and nucleolar shapes were often clearer with the RAD-Pap stain than with the Giemsa stain. However, whether samples were stained successfully with RAD-Pap should be carefully evaluated, because it still requires a complicated multistep procedure. An erythrocyte-free background is an advantage of RAD-Pap in contrast to traditional Pap, and this phenomenon was considered due to hemolysis of red blood cells in the rehydration process $[2,10]$. However, the presence of erythrocytes is often useful for comparison of cell size $[13,15]$. In addition, artificial erythrocyte-free background induces difficulty to evaluate the quality of samples. Therefore, we do not consider this phenomenon advantageous for veterinary diagnostic cytology.
In conclusion, the present study evaluated the usefulness of the RAD-Pap stain in a quantitative manner. The present RAD-Pap stain was successfully applied to canine and feline cytological smears, and it was demonstrated that RAD-Pap was superior for detection of anisonucleoliosis as a malignant criterion. This RAD-Pap stain could be routinely used as a supportive staining method in veterinary diagnostic cytology.

\section{REFERENCES}

1. Basolo, F., Baloch, Z. W., Baldanzi, A., Miccoli, P. and LiVolsi, V. A. 1999. Usefulness of Ultrafast Papanicolaou-stained scrape preparations in intraoperative management of thyroid lesions. Mod. Pathol. 12: 653-657. [Medline]

2. Chan, J. K. and Kung, I. T. 1988. Rehydration of air-dried smears with normal saline. Application in fine-needle aspiration cytologic examination. Am. J. Clin. Pathol. 89: 30-34. [Medline]

3. Christensen, E., Bofin, A., Gudmundsdóttir, I. and Skogvoll, E. 2008. Cytological diagnosis of basal cell carcinoma and actinic keratosis, using Papanicolaou and May-Grünwald-Giemsa stained cutaneous tissue smear. Cytopathology 19: 316-322. [Medline] [CrossRef]

4. Einstein, A. J., Yang, G. C., Silberfarb, J. B. and Gil, J. 1997. Effect of ultrafast Papanicolaou staining on nuclear and textural features in breast cancer cytology. Anal. Quant. Cytol. Histol. 19: 361-367. [Medline]

5. Jörundsson, E., Lumsden, J. H. and Jacobs, R. M. 1999. Rapid staining techniques in cytopathology: a review and comparison of modified protocols for hematoxylin and eosin, Papanicolaou and Romanowsky stains. Vet. Clin. Pathol. 28: 100-108. [Medline] [CrossRef]

6. Kamal, M. M., Kulkarni, M. M. and Wahane, R. N. 2011. Ultrafast papanicolaou stain modified for developing countries: efficacy and pitfalls. Acta Cytol. 55: 205-212. [Medline] [CrossRef]

7. Lemos, L. B., Baliga, M. and Cason, Z. 1997. Ultrafast Papanicolaou stain: one year's experience in a fine needle aspiration service. Acta Cytol. 41: 1630-1631. [Medline]

8. Mehta, N., Modi, L., Patel, T. and Shah, M. 2010. Study of cytomorphology of solid pseudopapillary tumor of pancreas and its differential diagnosis. J. Cytol. 27: 118-122. [Medline] [CrossRef]

9. Minato, H. 2000. Ultrafast-Papanicolaou stain on air-dried smears, with its application to intraoperative diagnosis. Med. Technol. 28: 1269-1273 (in Japanese).

10. Ng, W. F., Choi, F. B., Cheung, L. L., Wu, C., Leung, C. F. and $\mathrm{Ng}, \mathrm{C}$. S. 1994. Rehydration of air-dried smears with normal saline. Application in fluid cytology. Acta Cytol. 38: 56-64. [Medline]

11. Papanicolaou, G. N. 1942. A new procedure for staining vaginal smears. Science 95: 438-439. [Medline] [CrossRef]

12. Pérez, C. C., Rodríguez, I., Dorado, J. and Hidalgo, M. 2005. Use of ultrafast Papanicolaou stain for exfoliative vaginal cytology in bitches. Vet. Rec. 156: 648-650. [Medline]

13. Ranskin, R. E. 2001. General categories of cytologic interpretation. pp. 15-21. In: Canine and Feline Cytology: A Color Atlas and Interpretation Guide, 2nd ed. (Raskin, R. E. and Meyer, D. E. eds.), Saunders Elsevier; St Louis.

14. Schulte, E. and Wittekind, C. 1987. The influence of the wetfixed Papanicolaou and the air-dried Giemsa techniques on 
nuclear parameters in breast cancer cytology: a cytomorphometric study. Diagn. Cytopathol. 3: 256-261. [Medline] [CrossRef]

15. Tyler, R. D., Cowell, R. L., Baldwin, C. J. and Morton, R. 1999. Introduction. pp. 1-19. In: Diagnostic cytology and hematology of the dog and cat, 2nd ed. (Rick, L., Cowell, R. L., Tyler, R. D. and Meinkoth, J. H. eds.), Mosby Elsevier; St Louis.

16. Yang, G. C. 1994. The mathematical basis for the increased sensitivity in cancer detection in air-dried cytopreparations. Mod. Pathol. 7: 681-684. [Medline]

17. Yang, G. C. 1995. Ultrafast Papanicolaou stain is not limited to rapid assessments: application to permanent fine-needle aspiration smears. Diagn. Cytopathol. 13: 160-162 http://www. google.co.jp/url?sa=t\&rct=j\&q=Diagn+Cytopathol.\&sourc $\mathrm{e}=$ web\&cd $=1 \&$ ved $=0$ CCkQFjAA\&url $=$ http $\% 3 \mathrm{~A} \% 2 \mathrm{~F} \% 2 \mathrm{Fj}$ ournals.wiley.com $\% 2 \mathrm{~F} 8755-1039 \% 2 \mathrm{~F} \& \mathrm{ei}=\mathrm{dXLMTqraPO}-$ WmQWjnv2sDQ\&usg=AFQjCNG27u7E-kN1_ywj4bqrlK8LJzrTLg. [Medline] [CrossRef]

18. Yang, G. C. 2003. Long microvilli of mesothelioma are conspic- uous in pleural effusions processed by Ultrafast Papanicolaou stain. Cancer 99: 17-22. [Medline] [CrossRef]

19. Yang, G. C. H. 1995. Ultrafast Papanicolaou stain: a superior stain for fine-needle aspiration cytology applied in conjunction with the rehydration of air-dried smears by normal saline solution technique. Adv. Anat. Pathol. 2: 208-211. [CrossRef]

20. Yang, G. C. and Alvarez, I. I. 1995. Ultrafast Papanicolaou stain. An alternative preparation for fine needle aspiration cytology. Acta Cytol. 39: 55-60. [Medline]

21. Yang, G. C., Liebeskind, D. and Messina, A. V. 2006. Diagnostic accuracy of follicular variant of papillary thyroid carcinoma in fine-needle aspirates processed by ultrafast Papanicolaou stain: histologic follow-up of 125 cases. Cancer 108: 174-179. [Medline] [CrossRef]

22. Yang, G. C. and Hoda, S. A. 1997. Combined use of the "scratch and smear" sampling technique and Ultrafast Papanicolaou stain for intraoperative cytology. Acta Cytol. 41: 1513-1518. [Medline] [CrossRef] 